\title{
Abstract 74
}

\section{PRELIMINARY SPEECH PERCEPTION RESULTS FOR CHILDREN WITH THE 22- ELECTRODE MELBOURNE/COCHLEAR HEARING PROSTHESIS}

\author{
Cowan R.S., Dowell R.C., Pyman B., Dettman S.J., Dawson P.W., Rance G., Sarant J.Z., \\ Clark G.M. \\ Human Communication Research Centre, University of Melbourne, The Australion Bionic Eor \\ and Hearing Research Institute, Cochlear Implant Clinic, Royal Victorian Eye \& Ear Hospital, \\ Australia
}

The Cochlear 22-electrode cochlear prosthesis was first implanted in a child of the Cochlear Implant Clinic at the University of. Melbourne and Royal Victorian Eye \& Ear Hospital in 1985. Since that time, 42 children have received the device in Melbourne. Analysis of patient details shows that the majority of these children have a congenital as opposed to an acquired aetiology of hearing loss. In all but 3 coses, the children use 15 or more electrodes. In order to assist with evaluation of benefits to speech perception across the very heterogenous group of children, a six level hierachical classification scheme for speech perception performance levels was created. All of the children achieved a minimum of Category 2 (discrimation of suprasegmental information). In total, $59 \%$ of the children achieved Category 5 or 6 lopen-set recognition for unfarmiliar materials). Analysis showed that the majority of these children had more than one year of experience. In contrast, the majority of children in Category 2 are those with less than one year of experience with the device. 


\section{University Library}

\section{- M M I N E R VA A gateway to Melbourne's research publications}

Minerva Access is the Institutional Repository of The University of Melbourne

\section{Author/s:}

Sarant, J. Z.; Clark, Graeme M.;Cowan, Robert S. C.;Dowell, R. C.;Pyman, B. C.;Dettman, S. J.;Dawson, P. W.;Rance, G.

Title:

Preliminary speech perception results for children with the 22-electrode Melbourne / cochlear hearing prosthesis

Date:

1992

Citation:

Cowan, R. S. C., Dowell, R. C., Pyman, B. C., Dettman, S. J., Dawson, P. W., Rance, G., et al. (1992). Preliminary speech perception results for children with the 22-electrode Melbourne / cochlear hearing prosthesis. In International Symposium - Cochlear Implants New Perspectives, Toulouse.

Persistent Link:

http://hdl.handle.net/11343/26869 